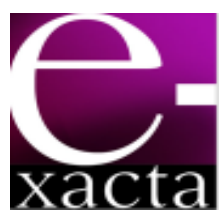

ISSN: 1984-3151

\title{
SÉCULO XXI CUPINZEIRO: ESTRUTURA E CONSTRUÇÃo SUSTENTÁVEL
}

\author{
Termite XXI Century: The Structure and Sustainable \\ CONSTRUCTION
}

\section{Ana Carolina Bitar Silva*1; Bruno Silva Assis ${ }^{1}$; Erick Guimarães Silva ${ }^{1}$; Kamala Karine Darc $^{1}$; Kelly A. Ferreira de Faria ${ }^{1}$; Otorino Otaviano Neto ${ }^{1}$; Sérgio Oliveira Martins Lage ${ }^{1}$; Miriam Cristina Pontello Barbosa Lima ${ }^{2}$ (Orientadora)}

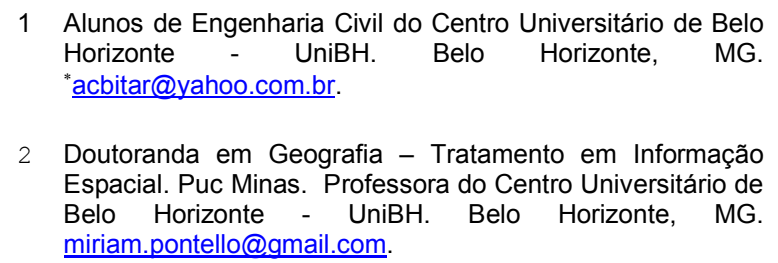

Recebido em: 24/09/2011 - Aprovado em: 30/09/2011 - Disponibilizado em: 13/10/2011

RESUMO: O presente trabalho constitui-se em um estudo acerca das construções sustentáveis, tendo como objetivo identificar algumas construções de animais e a partir delas, verificar a possibilidade de obter técnicas que podem ser aplicadas na construção civil sustentável. Ao longo do artigo são apresentadas as tipologias da Biomimética que trata-se do estudo das estruturas biológicas e suas funções, procurando aprender com a natureza soluções que podem ser aplicadas no cotidiano. É também uma ferramenta para impulsionar a inovação em sintonia com o meio ambiente e vem sendo chamada de "a nova revolução industrial". Além disso, este artigo apresenta as etapas do funcionamento da estrutura dos túneis e condutores de ar que o cupinzeiro possui e que podem ser utilizáveis na construção civil. Dessa forma, foi desenvolvido o projeto e uma maquete de um edifício comercial onde o sistema de ventilação dos andares foi inspirado no cupinzeiro.

PALAVRAS-ChavE: Cupinzeiro. Construções Sustentáveis. Sustentabilidade.

ABSTRACT: This work is in a study on sustainable building, aiming to identify some animals and constructs from them, verify the possibility of obtaining tecina that can be applied in sustainable construction. Throughout the article presents the types of Biomimetics that it is the study of biological structures and their functions, looking for solutions to learn from nature that can be applied in everyday life. It is also a tool to drive innovation in harmony with the environment and has been called "the new industrial revolution." Additionally, this article presents the steps of the operation of the structure of tunnels and air ducts to the mound and has may be usable in construction. Thus, the project was developed and a model of an office building where the ventilation system of the story was inspired by the mound.

KEYWORDS: Mound. Sustainable. Cosntruction Sustainability. 


\section{INTRODUÇÃO}

A natureza, cuja evolução é eterna, possui valor em si mesmo, independentemente da utilidade para o ser humano. Essa ideia central define a chamada ecologia profunda, cuja influência é hoje cada vez maior, e expressa à percepção prática de que o homem é parte inseparável do ambiente em que vive. Na nova era global, milhões de pessoas voltam a perceber que o sentimento de comunhão com a natureza. Não é coisa do passado ou um costume do tempo das cavernas. Ao contrário, deverá marcar as civilizações do futuro. Em qualquer tempo histórico, o convívio direto com a natureza foi e será um fator decisivo para o bem-estar físico e psicológico do ser humano.

Olhar a natureza e nela buscar inspiração para a ciência, a tecnologia, o design, a arquitetura, a medicina e etc, torna-se cada vez mais atraente. Por meio da biomimética, que estuda as estruturas biológicas e suas funções, é possível procurar e aprender com a natureza soluções que podem ser aplicadas no cotidiano. A biomimética é também uma maneira para impulsionar a inovação, em sintonia com o meio ambiente, e vem sendo chamada de "a nova revolução industrial". Alguns exemplos podem ser citados e vão desde turbinas eólicas inspiradas nas nadadeiras das baleias até o prosaico velcro criado em 1941, pelo engenheiro suíço George de Mestral, a partir da observação dos espinhos e ganchos das sementes de grama que se prendiam nos pêlos de seu cachorro.

No Brasil, um dos estudiosos acerca da biomimética é o designer Fred Gelli (2009), da agência Tátil Design, do Rio de Janeiro. Há 20 anos ele estuda o conceito e tenta aplicá-lo a embalagens, objetos e espaços físicos, que já lhe renderam vários prêmios de design. De modo geral, a biomimética tem sido muito utilizada em razão de seus aspectos funcionais, como o prédio na África inspirado em um cupinzeiro. Esse projeto permitiu uma redução de $65 \%$ no consumo de energia do edifício. "A biomimética pode ser uma grande aliada na busca pela sustentabilidade, pois se inspira na natureza e não tenta subjugá-la". Gelli (2009).

Outro exemplo de aplicação prática da biomimética na indústria é a borboleta do gênero "Morpho". Sua estrutura de cristais que refletem a luz já foi utilizada pela indústria têxtil e serviu de inspiração para uma linha de maquiagem que será lançada pela multinacional de cosméticos L"Oreal.

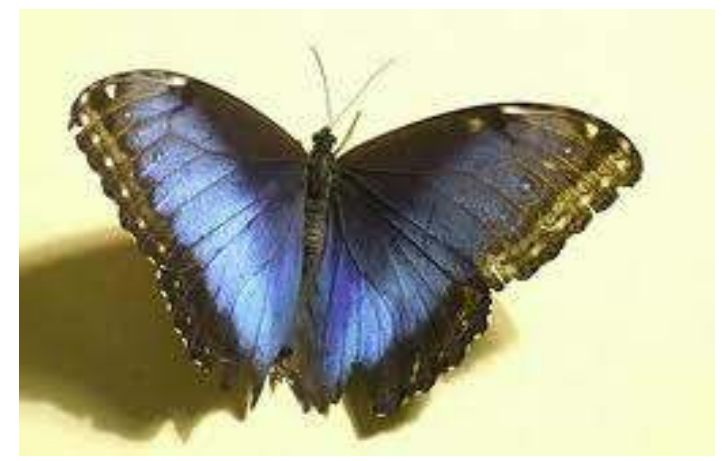

Figura 1: Borboleta do gênero Morpho.

Fonte: www.seresvivos.blogpost.com

A fabricante americana de carpetes interface, companhia que tem um plano abrangente para reduzir ao máximo seu impacto ambiental, também bebeu na fonte da biomimética. A empresa se inspirou na composição do solo da floresta para lançar carpetes em módulos, que podem ser repostos à medida que se desgastam, sem ser necessária a troca completa.

Um dos vários projetos em que Gelli trabalhou no Brasil foi a embalagens para cosméticos, que ainda não chegaram ao mercado, inspiradas no formato de folhas, com nervuras que permitiriam o aproveitamento total do produto.

Outra empresa que tem buscado inspiração na natureza é a Bausch \& Lomb, que fabrica produtos oftalmológicos. Entre os produtos biomimetizados está uma lente para correção de catarata inspirada no desenho do cristalino, que imita as características da superfície ocular. Em 2011, a empresa lança no Brasil uma solução de limpeza para lentes de contato com o $\mathrm{pH}$ da lágrima humana, o que deve reduzir a reação 
alérgica a esse tipo de produto. "Isso é bastante novo em oftalmologia. Mas num futuro próximo veremos inúmeras soluções da biomimética aplicadas à medicina", aposta Gary Orsborn diretor de cuidados médicos da Busch \& Lomb nos EUA e responsável pelo desenvolvimento dos produtos.

Os produtos da natureza em geral são flexíveis e leves, mas incrivelmente fortes, inovadores, inteligentes e são fabricados sem produzir poluição como, por exemplo, as células solares mais eficientes inspiradas em olhos de mariposas: novo filme para a cobertura das células solares que permite diminuir a quantidade de luz refletida ajudando a captar mais energia solar é criado, baseando-se na microestrutura do olho da mariposa.

Os olhos das mariposas, estruturas adaptadas à visão noturna, estão cobertos com uma camada repelente à água, uma espécie de revestimento anti-reflexo que faz dos olhos destes insetos uma das superfícies menos reflexivas da natureza. Tal característica, que ajuda este inseto a se esconder melhor dos predadores no escuro, inspirou cientistas a elaborarem um filme que maximiza a captação de energia solar.

Os novos desafios enfrentados pela indústria da construção civil, particularmente no setor edificações, podem ser resumidos na necessidade de conjugar-se redução de custos com a elevação dos níveis de qualidade de processos e produtos. $\mathrm{Na}$ construção sustentável, os engenheiros civis e arquitetos podem procuram usar tecnologias ecológicas nas obras para preservar o meio ambiente e poupar os recursos naturais.

O objetivo deste artigo é pesquisar a estrutura do cupinzeiro, como suas entradas de ar que permitem ventilação, tirando o ar quente e fazendo com que entre $\mathrm{o}$ ar frio conforme a Figura 2 .
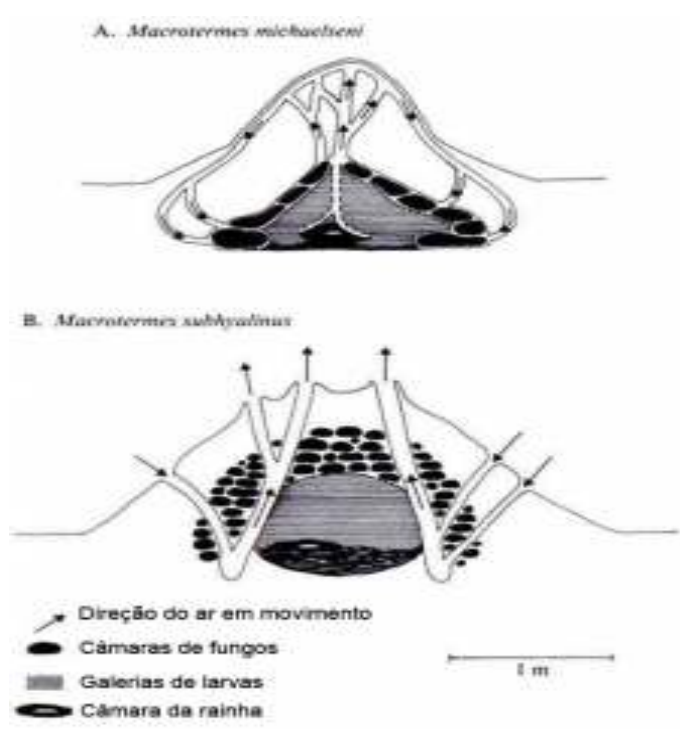

Figura 2. O cupinzeiro e o sistema de ventilação.

Fonte: Inhabitat.( http://inhabitat.com/building-modelledon-termites-eastgate-centre-in-zimbabwe/)

Além disso, é objetivo também, desenvolver um projeto de um prédio comercial, cuja estrutura de ventilação foi baseada no cupinzeiro, além de contar com o aproveitamento de água, economia de energia elétrica por meio de lâmpadas específicas.

A metodologia aplicada é o estudo da natureza com base em seus exemplos, sendo observado o cupinzeiro de modo a reproduzir a sua troca de calor através de sistemas de corrente de convecção.

\section{CUPINZEIRO}

O presente artigo foi elaborado a partir da observação do cupinzeiro que por avaliação em diversos exemplos que as soluções arquitetônicas foram surpreendentes, eficazes e sustentáveis. Iniciativas como os projetos Termes, organizado por Rupert Soar (2009), de monitoramento e aprendizado estrutural de formas naturais resultam em soluções arquitetônicas surpreendentes, eficazes e sustentáveis. Esse projeto da Universidade de Loughborough, na Inglaterra, realiza um mapeamento tridimensional da estrutura de 
cupinzeiros, de forma a estudar sua arquitetura e funcionamento. Tudo feito com a ajuda de tecnologia de ponta.

De posse dos modelos detalhados, cientistas podem entender como funciona a estrutura de túneis e condutos de ar que realiza troca de gases, mantém a temperatura e regula a umidade. Objetiva-se chegar a padrões utilizáveis na construção de edificações autoregeláveis.

O Eastgate Center, na cidade de Hare, no Zimbábue, projeto de autoria do arquiteto Mick Pearce, em parceria com a ARUP engenharia, não possui um sistema convencional de ar condicionado ou aquecimento, mas mesmo assim, mantém ao longo de todo o ano sua temperatura regulada com uma economia dramática no consumo de eletricidade, tudo graças a um design que seguiu os princípios da biomimética, por exemplo, a Figura 3.

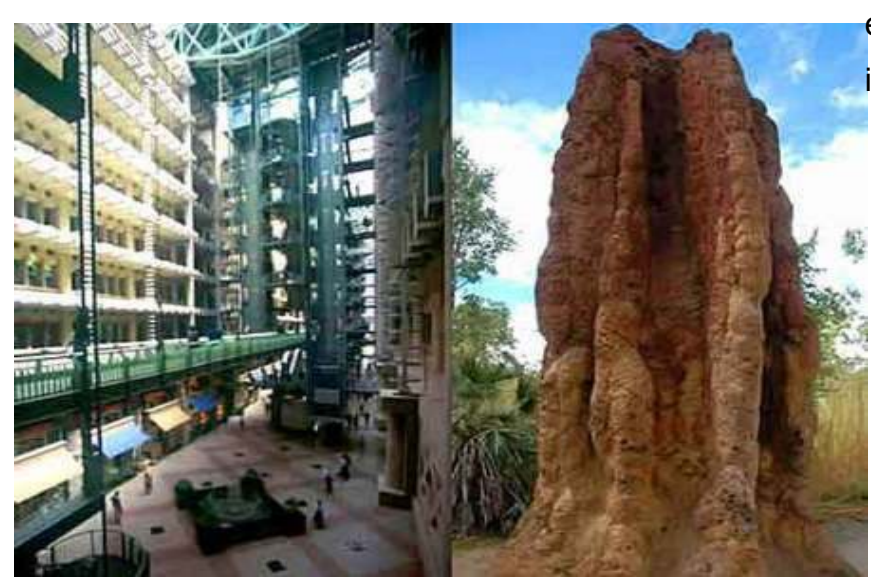

Figura 3. Eastgate Center e cupinzeiro.

Fonte: Inhabitat.( http://inhabitat.com/building-modelledon-termites-eastgate-centre-in-zimbabwe/)

Os cupins, no Zimbábue, Figura 3, constroem montes imensos, onde cultivam fungos, já que é sua fonte principal de alimento. Esses fungos devem ser mantidos a exatos $30,55^{\circ} \mathrm{C}$ e a temperatura externa varia enormemente, de $1,6^{\circ} \mathrm{C}$, durante a noite, a $40^{\circ} \mathrm{C}$ durante o dia. Os cupins conseguem estabilizar a temperatura por meio de um sistema que está constantemente abrindo e fechando uma rede de túneis de ventilação para aquecimento ou resfriamento.

Com um sistema de correntes de convecção cuidadosamente ajustado, os cupinzeiros sugam ar através da parte inferior dos montes, leva-o a galerias inferiores com paredes úmidas, para em seguida subir por um túnel, direto ao topo.

Os cupins estão constantemente cavando novos túneis e fechando antigos, de forma a regular a temperatura. O Eastgate Center, no Zimbábue, cuja estrutura é predominantemente de concreto, funciona de forma similar. A ventilação que adentra a edificação é resfriada ou aquecida, a depender do que estiver mais quente o ar ou o próprio concreto da edificação como mostra a Figura 4. Essa ventilação é canalizada para os escritórios ou para o próprio Shopping Center, antes de sair pelo sistema de exaustão natural (similar a uma chaminé). Trata-se de um conjunto que engloba duas edificações separadas por um espaço aberto, com iluminação zenital e aberto à ventilação

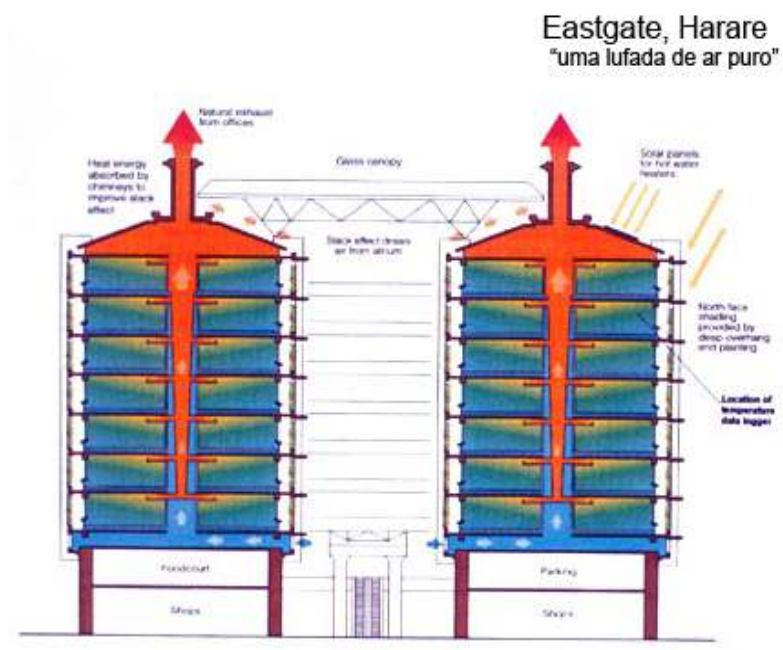

Figura 4. Eastgate Center sua estrutura.

Fonte: Inhabitat.( http://inhabitat.com/building-modelledon-termites-eastgate-centre-in-zimbabwe/) 
O Eastgate Center consome, espantosamente, menos de $10 \%$ da energia que um prédio convencional. Além de ser um avanço ecológico, essa economia (de cerca de 3,5 milhões de dólares no empreendimento) resulta em aluguéis $20 \%$ menores que os das edificações circundantes. A proposta para este trabalho é criar um projeto semelhante ao Eastgate Center, por meio do projeto de um edifício seria usado essa mesma estrutura para canalização de entradas de ar e ventilação, aproveitamento da luz solar e redução de energia elétrica.

\section{O PROJETO DO EDÍFICO COMERCIAL}

Aliado a uma boa combinação de técnicas e uso responsável do meio ambiente, o projeto desenvolvido apresenta uma arquitetura mais sustentável. Uma construção sustentável prevê que os materiais usados:

- dêem preferência para os que venham de locais próximos;

- sejam sintéticos, naturais e ou transformados, devem ser produzidos para ser usados até o fim da vida útil;

- sejam adequados para a reciclagem, reuso e reutilização;

- primem por aqueles compostos de substâncias não tóxicas, não nocivas e benéficas na decomposição;

- tenham sido feitos sem agredir o meio e ou deturpar as ordens sócias e culturais. Economicamente vantajoso ao lugar e região na qual é produzido;

- sejam materiais de ordem naturais, porém renováveis. Utilizados e mantidos para o uso das sociedades que ainda estão por vir.

- criem condições para novos padrões sustentáveis de consumo e sejam eficientes.
- não sejam transgênicos.

- não poluam o meio na qual é utilizado.

- colaborem para o fim das devastações ambientais.

Os produtos e equipamentos utilizados nesses tipos de edificação devem conter os mesmos conceitos dos materiais acima, sejam eles industrializados, artesanais ou manufaturados. Ou seja, devem:

- propiciar o reuso de suas partes;

- gerar sua própria energia sem produzir resíduos ou funcionar, através de alguma fonte de energia sustentável;

- aliar suas funções eficientemente com as condições naturais do lugar na qual é usado.

Essa estrutura também prevê melhorar a circulação de ar, redução de ar-condicionado, de materiais renováveis, dos gases atmosféricos, diminuição de doenças biológicas entre outros benefícios. Dessa forma, a ventilação é canalizada para os apartamentos, antes de sair pelo sistema de exaustão natural (similar a uma chaminé). Trata-se de um conjunto que engloba duas edificações separadas por um espaço aberto, com iluminação zenital e aberto à ventilação local.

Importante lembrar que tanto materiais ou produtos utilizados nestas construções não só devam ser fabricados com responsabilidade, mas, quem os usa têm uma parcela fundamental para estes continuarem sendo sustentáveis.

A seguir encontram-se alguns materiais e produtos que foram utilizados para a construção do projeto:

\section{Fibras vegetais}

São excelentes materiais que substituem as fibras de vidro e sintéticas. Pode ser misturada ao concreto para agregar maior resistência, serem usadas para fazer telhas, tapumes, revestimentos acústicos e térmicos, painéis, tecidos, tapetes e carpetes. 


\section{Solo Cimento}

É um tipo de cimento para argamassa ou estrutura, adequado para uso em revestimentos de pisos e paredes devido à elasticidade, usado para pavimentação, em muros de arrimo, confecção de tijolos e telhas sem que haja uma queima prévia.

\section{Telhado Verde}

As coberturas verdes, ou telhados ecológicos, e jardins suspensos existem há muito tempo na história da humanidade. No século VI A.c. na Babilônia, o uso dessa técnica já era conhecida. No século XIX em Berlim, as casas rurais eram cobertas por uma camada de terra, a fim de evitar incêndios, nessa camada de húmus, a vegetação acabava crescendo e cobrindo os tetos.

Telhado verde é uma técnica de arquitetura que consiste na aplicação e uso de solo e vegetação sobre uma camada impermeável, geralmente instalada na cobertura de residências, fábricas, escritórios e outras edificações.

Com a urbanização crescente as áreas verdes vão ficando cada vez menores e uma solução para aumentar as áreas verdes é usar os telhados para plantar gramas, flores, etc. a fim de melhorar o ambiente com as seguintes vantagens:

- melhorar a qualidade do ar;

- providenciar habitat para pássaros e insetos;

- melhorar o nível de umidade;

- reduzir as expansões e contrações dos tetos em concreto armado;

- reduzir os custos de refrigeração na época de calor;

- deter as enchentes;

- melhorar a paisagem;

- diminui a ilha de calor.
Importante ressaltar que como todas as áreas verdes, uma cobertura desse tipo demanda manutenção adequada, pois, por se tratar de um organismo vivo, essa vegetação cresce e produz um excesso de folhas mortas que por vezes entopem ralos, podem subir nas paredes ou entrar em frestas de janelas e portas. Como demonstra as figuras 5 e 6 .

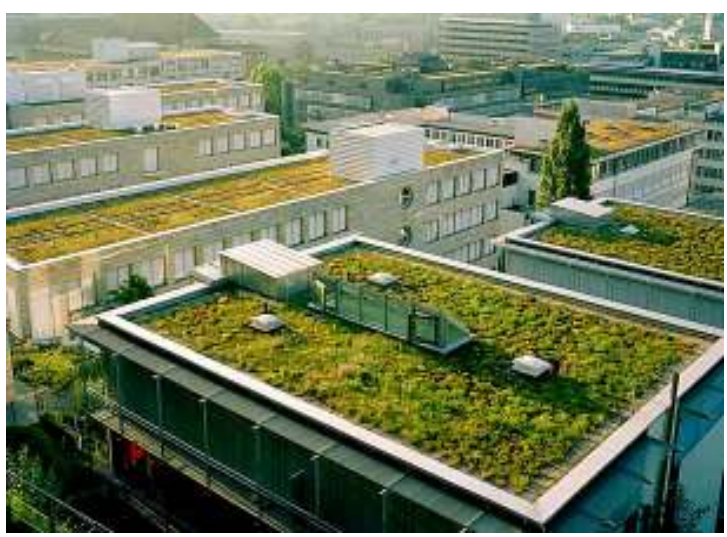

Figura 5. Telhados verdes.

Fonte: Planeta Sustentável

(http://planetasustentavel.abril.com.br/noticia/casa/cont eudo_264394.shtml> Acesso em: 12 maio 2011)

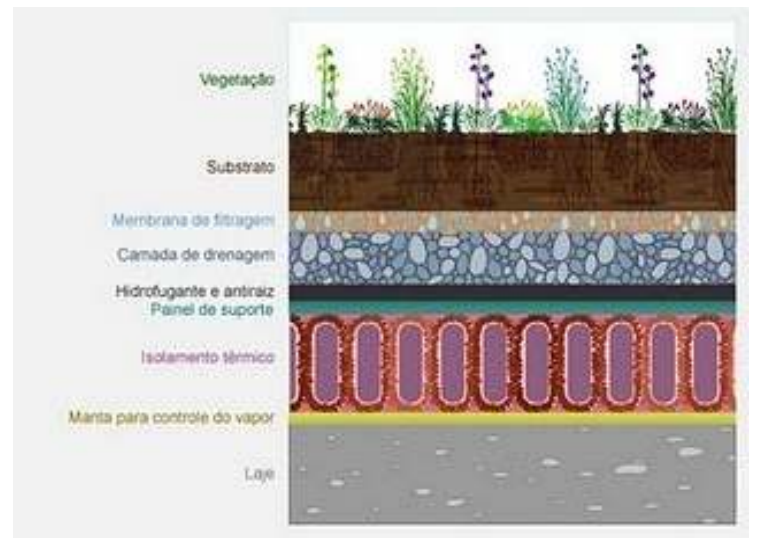

Figura 6. Corte esquemático de um telhado verde. Fonte: http://www.ecobuilding.com.br/

O projeto desenvolvido trata-se de um edifício comercial, de três andares, tendo como principal 
característica o aproveitamento da ventilação natural, pois o mesmo foi construído a partir da inspiração do funcionamento de ventilação do cupinzeiro da região africana. Além disso, esse projeto possui características de um imóvel sustentável, já que por meio de funções de aproveitamento de água e energia, promove economia de retirada de recursos naturais.

O projeto foi baseado na estrutura básica de um cupinzeiro do Zimbábue, cuja principal função é a ventilação, pois os cupins armazenam fungos em sua estrutura sendo assim necessária a troca de temperatura. Este projeto contou com a construção de uma maquete, cujos materiais necessários foram: 5 tábuas cortadas com $0,60 \mathrm{~cm}$ para a base; 3 sacos de massa pronta; 12 barras de ferro de $0,5 \mathrm{~mm} ; 4$ barras de ferro de $6.3 \mathrm{~mm}$; 54 tijolos; pé direito com $77 \mathrm{~cm}$ altura, $41,5 \mathrm{~cm}$ de largura, $28,5 \mathrm{~cm}$ de altura livre de sala, $36,5 \mathrm{~cm}$ de comprimento de sala livre; $3,5 \mathrm{~cm}$ de viga; $2 \mathrm{~cm}$ de laje; $2^{\circ}$ pavimento com $10 \mathrm{~cm}$ de viga; 2 $\mathrm{cm}$ de laje com 41,5 cm de largura, 32,5 de largura e $35 \mathrm{~cm}$ de comprimento. Conforme a Figura 6.

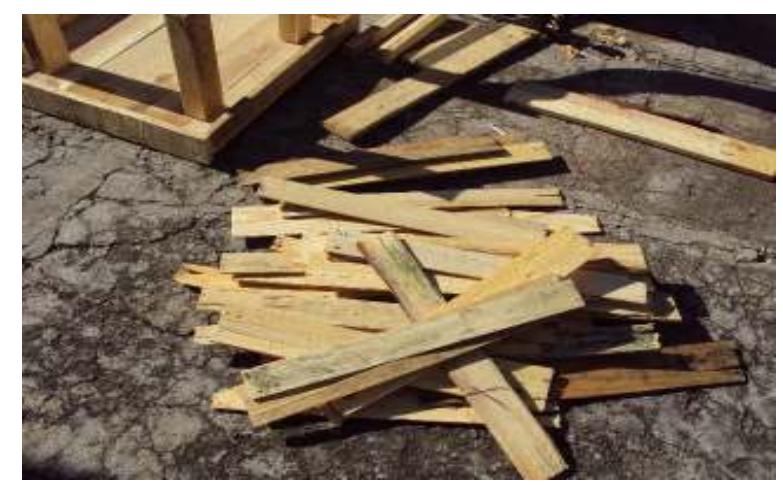

Figura 6. Materiais utilizados.

Por se tratar de um edifício comercial, foi projetado para locação de salas e andares para consultórios, escritórios de advocacia entre outros. A Figura 7 representa a construção do protótipo:

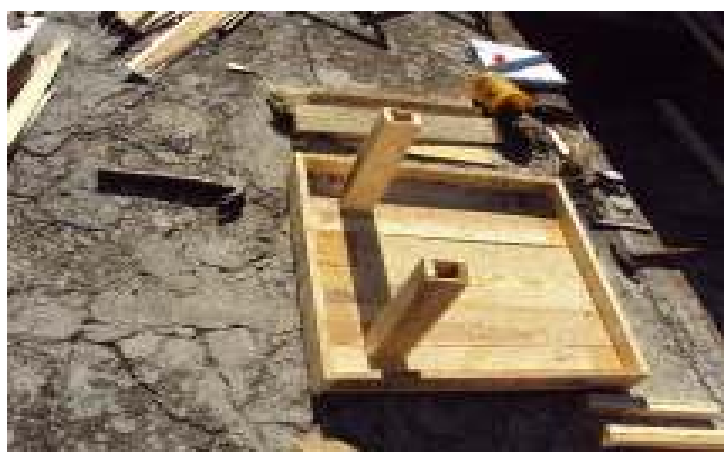

Figura 7. Maquete inicial do projeto do edifício em construção.

Alguns pontos positivos e negativos podem ser destacados neste projeto: esse prédio foi baseado em um projeto sustentável, sendo assim, ele contribui para reduzir os danos causados pela retirada de matéria prima na natureza, já economiza na energia elétrica por causa da utilização de vidros na fachada, na água, por meio da captação e na reciclagem da água, alem de reduzir a utilização do ar condicionado pelo seu sistema de ventilação central.

Em relação aos pontos negativos, como em qualquer construção civil, é impossível não considerar a degradação do meio da área a ser construída. Também deve-se considerar a retirada de solo, o desperdício de muitos materiais na construção e a poluição do meio ambiente com o descarte dos resíduos sólidos.

As figuras do protótipo 8 e 9, apresentam a maquete na sua fase intermediária de desenvolvimento:

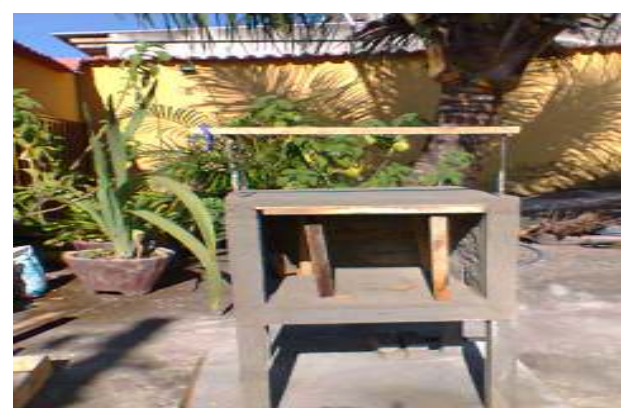

Figura 8. Maquete em desenvolvimento. 


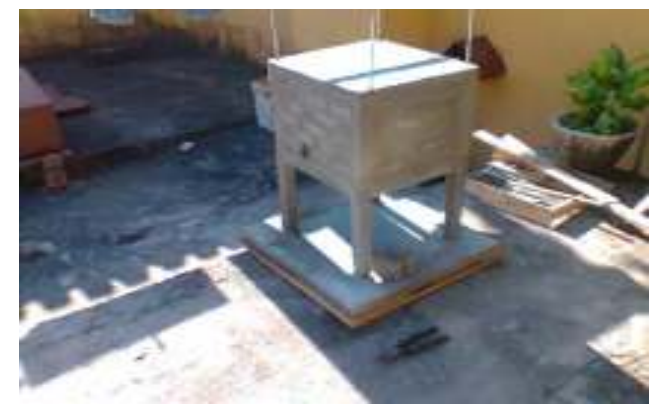

Figura 9. Maquete em desenvolvimento.

O projeto foi concebido com a aplicação dos conceitos da biomimética (utilização de observações de construções ou situações observadas da natureza para construção civil) e de sustentabilidade (utilização dos recursos de forma a manter o desenvolvimento atual sem prejudicar as gerações futuras). A proposta de viabilidade do projeto é relativamente simples. Utilizando dutos com revestimento de lã de rocha, para evitar perda de calor, que conduzem o ar quente a um duto central que converge o ar para a atmosfera, promove a circulação de ar dentro das salas.

Para a fabricação desses dutos é necessário aproximadamente 100 chapas galvanizadas de 1/8" de $3000 \times 1200 \mathrm{~mm}$ mais o custo de mão de obra para montagem do sistema de revestimento térmico. Para implantação de um sistema de ar condicionado no projeto, cada uma das 12 salas deve possuir:

Sistema de ar condicionado de 60.000 BTU's

Custo: Evaporador $\mathrm{R} \$ 3120$ reais.

Condensador $\mathrm{R} \$ 4680$ reais.

Instalação $\mathrm{R} \$ 800$ reais.

Consumo de energia $/$ mês $=212$ kw/mês.

Custo com energia elétrica é estimado em R\$126,82 reais. Esses valores são previstos para cada sala, cujo total estimado é de $\mathrm{R} \$ 8.600,00$.
O custo total, estimado, para instalação do equipamento em todo o prédio é $\mathrm{R} \$ 103.200$ reais. O custo mensal do prédio em reais com energia elétrica para ar condicionado é $\mathrm{R} \$ 1521,84$ reais. O custo total de manutenções preventivas nos equipamentos sem contar com quebras e manutenções avulsas seria estimado em $\mathrm{R} \$ 1521,84$ reais.

No sistema com base na biomimética seriam gastos 100 chapas galvanizadas $3000 \times 1200 \mathrm{~mm}$ ao custo unitário de $\mathrm{R} \$ 160$ reais.

Custo total: $\mathrm{R} \$ 16.050,00$ reais.

Custo com mão de obra para montagem: $\mathrm{R} \$ 18.000$ reais.

Custo com mão de obra para revestimento térmico: $\mathrm{R} \$ 27.000$ reais

Custo total para implantar o sistema é: $\mathrm{R} \$ 61.050,00$ reais.

Custo de manutenção anual de inspeção: $R \$ 950,00$ reais (sem contar custos com peças).

A iluminação segundo a norma 5410 ABNT uma edificação destinada a fins comerciais deve possuir uma iluminância de 500lux ambiente. Após os cálculos foi verificado que será necessário 8 luminárias $4 \times 40 \mathrm{w}$ distribuídas simetricamente no recinto. Para comparação caso fosse usado lâmpadas incandescentes seria necessário 20 luminárias 2x100w, ou seja, 2 lâmpadas de 100w para cada luminária.

A potência total a ser instalada no caso de iluminação fluorescente é de 1280w. No caso de utilizar as lâmpadas incandescentes a potência instalada seria de 2000w. A economia direta seria de 720 w de potência instalada. Isso representa $187,2 \mathrm{kw} / \mathrm{h}$ a menos de gastos gerando economia de 113,05 reais para cada sala, considerando um uso de $10 \mathrm{Hs}$ diárias da iluminação e o custo do kW/h de 0,60393554. Para esse cálculo foi feito uma média para cada sala e dividido o gasto coma iluminação da área comum 
igualmente para as mesmas e já acrescentado ao cálculo acima.

3.1 A PLANTA BaiXa DO PROJeto DO EDIFícIO SUSTENTÁVEL

No sentido de proporcionar melhor visualização acerca do projeto desenvolvido, encontram-se nas figuras 10 a 12, a planta do projeto do edifício comercial.

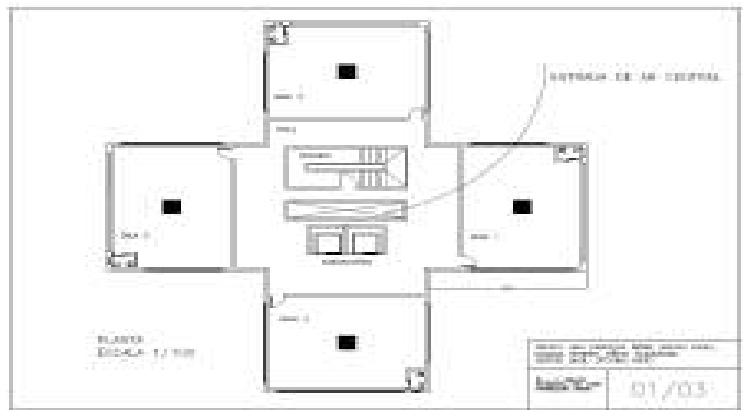

Figura 10. Planta baixa do projeto do edifício comercial.

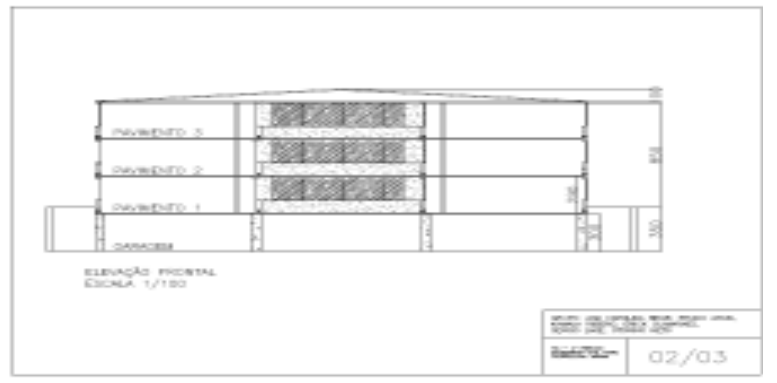

Figura 11. Planta baixa do projeto do edifício comercial.

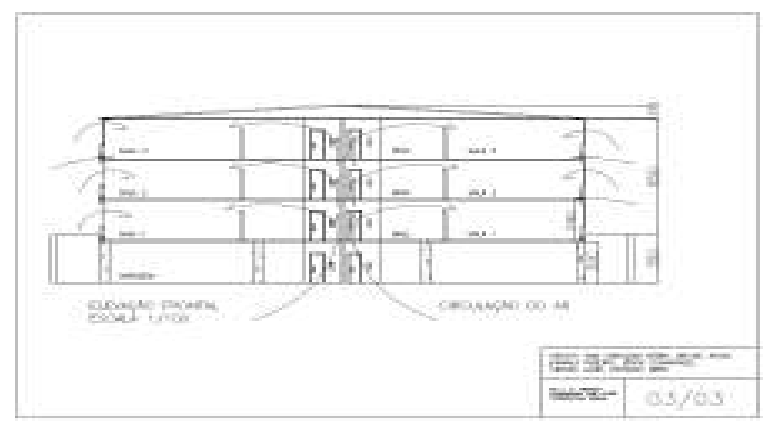

Figura 12. Planta baixa do projeto do edifício comercial.
Mediante do desenvolvimento deste artigo, notou-se a grande importância da sustentabilidade econômica, social e ambiental para a continuidade da vida humana em vista das degradações ambientais que a urbanização e o modo de vida capitalista estão causando.

O consumo desenfreado dos recursos naturais por uma parte da população são fatores extremamente combatidos no âmbito da sustentabilidade social e o artigo desenvolvido mostra que aos poucos a postura das empresas vem mudando, incluindo também o setor de construção civil. Como a quantidade de resíduos deixados por construções é grande, tais questões ambientais têm ocupado gradativamente mais espaço nos problemas dos países, desenvolvidos ou não.

Como toda construção exige uma demanda por materiais, é de extrema importância que os profissionais envolvidos se preocupem em optar por produtos de locais próximos, recicláveis, não tóxicos e que não poluam tanto o meio no qual serão utilizados.

Não esgotar os recursos naturais, preservando-os para as gerações futuras, utilizar-se de soluções tecnológicas inteligentes (que promovam e reduzam a poluição), além do bom uso de água e de energia também são fatores igualmente importantes e devem ser considerados na elaboração de qualquer edifício.

Entrelaçadas à sustentabilidade social também estão às sustentabilidades econômica e ambiental. Essas últimas estão relacionadas com capacidade de produção, distribuição e utilização de forma equitativa das riquezas produzidas pelo homem, o que envolve no momento principalmente a mudança para o consumo de energias renováveis e não agressivas à natureza.

O artigo apresenta a importância da biomimética para a área de edificações, além de mostrar também que uma construção pode ser baseada num cupinzeiro,e dessa forma favorecer a sustentabilidade. 
Essa nova área de pesquisa estuda as estruturas biológicas na tentativa de aplicar alguns aspectos $\mathrm{e}$ rotinas da vida animal como alternativa para melhorar cotidiano dos seres humanos, principalmente no que tange a economia de recursos naturais e matéria-prima.

Uma economia sustentável é sem dúvida a base para uma sociedade estável e mais justa, onde é possível criar oportunidades também para melhorar todos os outros setores.

Uma vez que a sociedade em questão adota medidas sustentáveis para o seu desenvolvimento, conseqüentemente torna-se mais livre da dependência de recursos e aquisições de outras nações ou de outros blocos econômicos. Assim, pode-se verificar na Figura 13, o protótipo do edifício finalizado.

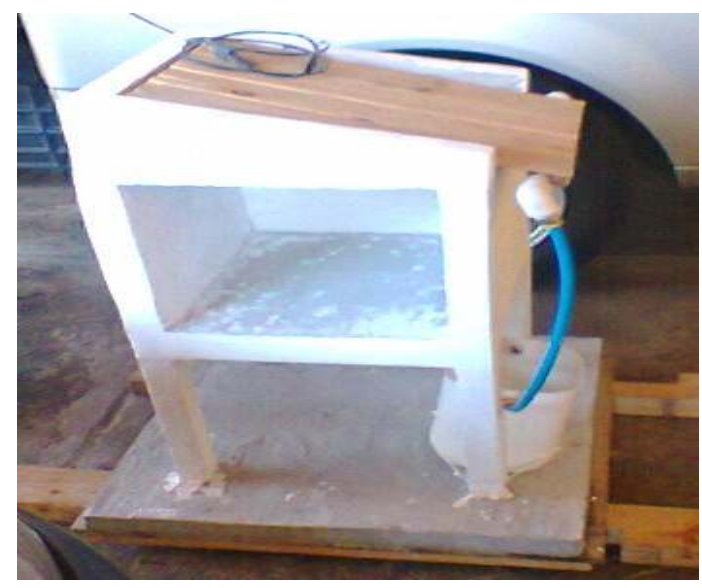

Figura 13. Conclusão do protótipo.

\section{Conclusão}

O artigo desenvolvido possibilitou o estudo das estruturas biológicas e suas funções, a biomimética, onde foi possível aprender com a natureza algumas possíveis soluções que podem ser aplicadas na construção civil.

A estrutura desenvolvida no protótipo foi baseada nos estudos do cupinzeiro, buscando alcançar o mesmo sistema de arrefecimento do ar, tendo como principal característica a ventilação, além de se tratar de um imóvel ecológico e sustentável pelas funções de aproveitamento de água e energia e a utilização de novas técnicas, tornando a engenharia civil mais sustentável.

Concluiu-se assim, que a escolha da técnica mais adequada para a região deve estar associada à comunidade servida, sempre visando o aproveitamento dos recursos.

Durante a realização desse projeto, foi possível promover a interdisciplinaridade por meio das disciplinas tais como a: Ética que foi possível entender como trabalhar de forma correta e prática buscando a forma mais responsável dentro de um grupo e atuando dentro dele; a de Ciências do Ambiente que ajudou a compreender como poderia usar o cupinzeiro, não só como inspiração, mas que o mesmo seria grande fonte de informação do solo que poderia ser trabalho, já que a terra que o cupim joga para fora, fornece informações sobre o solo; já a disciplina Algoritmo e Estruturas de Dados, foi produzido o Algoritmo 1, que calcula as dimensões dos cômodos do edifício deste projeto.

\section{Algoritmo 1 - Cálculo de Área do Projeto}

Início

//declaração de variáveis

declare largura, comprimento, dimensões, área, área total numérico

//Entrada de Dados

escreva ("Entre com a dimensões do cômodo")

leia (largura,comprimento)

//Processamento de dados

área $=$ largura * comprimento

área total = área + área + área + área.

escreva ("A área total dos cômodos do edifício é: " + área total)

Fim Algoritmo 
AGRADECIMENTOS

Os autores agradecem aos professores Miriam Cristina Pontello Barbosa Lima, Alexandre A. Washington, Fernando Pereira de Faria, Mônica
Pessoa Neves, Sandra Maria Rodrigues de Morais e Tarcizo José dos Santos Junior, que colaboraram direta ou indiretamente para o desenvolvimento deste projeto.

\section{REFERÊNCIAS}

SENAI-MG - Apostila instalações elétricas prediais Howstuffworks/ Como tudo funciona. Disponível em:<http://ambiente.hsw.uol.com.br/> Acesso em: 05 mar. 2011

ARMANDO CLIMA TECNOLOGIA EM CLIMATIZAÇÃO DE AMBIENTE LTDA. Site ABNT, YORK.

ARQUITETOGEEK. Disponível em:

http://arquitetogeek.wordpress.com/2009/11/15/biomim etica-arquitetura-2/> Acesso em: 05 mar. 2011

BONABEAU, E. Theraulaz, G., Deneubourg, JL., Franks, NR, Rafelsberger, O., Joly, JL.e Blanco, S. A model for the emergence of pillars, walls and royal chambers in termite nests. Philosophical Transactions of the Royal Society of London. 1998.B. 353,pp 15611576.

BRISTOW, KL \& Holt, JA. Can Termites Create Local Energy Sinks to Regulate Mound Temperature? Journal of Biology térmica, Vol.12, pp 19-21.1997.

ECO-CONSTRUÇÃO. Disponível em:

$<$ http://www.ecoconstrucoes.com/?p=120> Acesso em: 15 de abr. 2011

ESTADÃO. Disponível em:

http://www.estadao.com.br/estadaodehoje/20101121/no

t_imp643094,0.php> Acesso em: 12 maio 2011.

INHABITAT - Disponível em:

$<$ http://inhabitat.com/building-modelled-on-termiteseastgate-centre-in-zimbabwe/ > Acesso em 05 mar 2011.

KORB, J. e LINSENMAIR, KE. Ventilation of Termite Mounds: New Results Require a New Model, Behavioral Ecology, vol. 11, PP 486-494. 2000.
LUSCHER, M. Air-conditioned termite nests.. Sci. Sou. 205, PP 138-145. 1961.

NASSRALLAH, Márcia. Designer de interiores. Disponível

em:<http://marcianassrallahdesignerdeinteriores.blog.te rra.com.br/tag/biomimetica/> Acesso em: 22 maio 2011

NATUREZA ECOLÓGICA. Disponível em: <http://www.naturezaecológica.com> Acesso em: 07 jun. 2011

PLANETA SUSTENTÁVEL. Disponível em: <http://planetasustentavel.abril.com.br/noticia/casa/cont eudo_264394.shtml> Acesso em: 12 maio 2011

PORTOBELLO. Disponível em: <http://blogportobello.com.br/tag/telhado-verde/> Acesso em: 05 mar. 2011

RECRIAR COM VOCÊ. Disponível em: http://www.recriarcomvoce.com.br/blog_recriar/vidasecreta-da-natureza/> Acesso em: 22 maio 2011

SUPER ABRIL. Disponível em: http://super.abril.com.br/blogs/planeta/biomimetica-aindustria-sustentavel-imita-a-natureza/> Acesso em: 07 jun. 2011

THE SANDKING. Disponivel em: $<$ http://www.sandkings.co.uk/>. Acesso em: 5 de março de 2011.

WIKIPÉDIA. Disponível em: <http://pt.wikipedia.org/wiki/Telhado_verde> Acesso em: 15 maio 2011. 